\title{
Large Plaque Parapsoriasis
}

National Cancer Institute

\section{Source}

National Cancer Institute. Large Plaque Parapsoriasis. NCI Thesaurus. Code C3670.

A variant of parapsoriasis in which the plaques are large. 